IIUM JOURNAL OF EDUCATIONAL STUDIES, 9:2 (2021) 3-5

Copyright $($ C IIUM Press

ISSN: 2289-8085

\title{
Book Review: History, Theory and Practice of Philosophy for Children
}

TITLE OF BOOK: History, Theory and Practice of Philosophy for Children

Editors: Saeed Naji and Rosnani Hashim

London \& New York: Routledge Research in Education, 2017, 232 pages

COVER: Paperback

ISBN: 978-1-138-63162-5 (hbk), 978-1-315-20873-2 (ebk)

\author{
Reviewed by: Maryam Jahedi \\ Department of Language and Humanities Education, \\ Faculty of Educational Studies, \\ Universiti Putra Malaysia, \\ Selangor, Malaysia \\ jahedi73@gmail.com
}

The editors of History, Theory and Practice of Philosophy for Children, Drs. Saeed Naji and Rosnani Hashim are distinguished scholars and founders of Philosophy for Children (P4C) movement in Iran and Malaysia, respectively. Dr. Naji is an Iranian scholar and a faculty member at the Institute for Humanities and Cultural Studies (IHCS) in Tehran and a P4C expert. Dr. Hashim is Professor of Social Foundations of Education at the Faculty of Education, International Islamic University Malaysia (IIUM) and the founder of The Center for Teaching Thinking. The editors noticed that the P4C Program was compatible with their own culture and tradition and tried to introduce it in their own countries. Their mutual interest in incorporating philosophical inquiry into Muslim education led them to develop this work to create a better environment for future generations.

Philosophy for Children can be engaging and inspiring. To produce this work, the editors interviewed the leading founders and pioneers of the P4C movement around the world. Their profound knowledge and interest in Philosophy for Children helped them to ask fundamental, thoughtful and exploratory questions to lead the discussion in such a way that is lucid and appealing to the readers. The strengths of the book lie on the structure of the interview questions, which can draw on stimulating ideas, as well as the chapter focus, which allows the readers to identify the section relevant to their research questions and interests. This collection of lively interviews and dialogues, which is worldwide in scope, is divided into five parts, including 25 chapters, ranging from the genesis of the $\mathrm{P} 4 \mathrm{C}$ movement to its global implementation. Each chapter is devoted to one of the experts in the field, providing a comprehensive introduction to the P4C Program.

Part I, Historical, Philosophical and Theoretical Roots, dedicates seven chapters to the origin of the $\mathrm{P} 4 \mathrm{C}$ movement and its philosophical and theoretical bases via interviews with the leading founders, including Matthew Lipman, Ann Margaret Sharp, Gareth B. Matthews and Roger Sutcliffe. It begins with the introduction of the P4C Program and its development and argues that $\mathrm{P} 4 \mathrm{C}$ is the most influential approach to improving children's thinking. It provides 
recommendations for the necessary steps to be taken to contemplate the use of $\mathrm{P} 4 \mathrm{C}$ and proceeds to the discussion of the traditional and reflective paradigms of education, the characteristics of philosophical novels and the differences between P4C novels, philosophical texts and other novels for children. Besides, it contrasts Philosophy for Children and Philosophy with Children $(\mathrm{PwC})$ and argues that $\mathrm{P} 4 \mathrm{C}$ aims to reconstruct the history of philosophy through stories and manuals, whereas $\mathrm{PwC}$ is not devoted to the use of planned and sequenced syllabus. Moreover, it explains why school administrators resist the new paradigm of education called for by $\mathrm{P} 4 \mathrm{C}$ and reveals the appropriate age for the teaching of philosophy. It also describes the relationship between philosophical inquiry and scientific inquiry, as well as the connection between P4C and reasonableness. Surprisingly, it rejects Piaget's assumptions on children's intellectual development and points out the shortcomings of his viewpoints. In other words, unlike Piaget's theory of psychological development which has no place for philosophical thinking in children under 12 years old, philosophical inquiry claims that children have philosophical thoughts at a younger age. Finally, it gives a comprehensive overview of PwC by one of the PwC-leaders.

Part II, Specialized Uses of Philosophical Dialogues, comprises three chapters with the focus on the importance of philosophical dialogues in teaching philosophy and other subjects, such as morality and sciences. It discusses the P4C Program for early childhood education in addition to its contributions to the teaching of science and moral education. Furthermore, it introduces a new approach in teaching philosophy that incorporate books that vary in structure from Lipman's in such a way that the text is overtly philosophical and can be used by teachers without formal philosophy training and can also be easily taught in other countries, whereas in Lipman's materials, philosophical content is mainly found in the exercises and teacher manuals. Moreover, it points out that picturebooks can be used from the early ages to university level and more in $\mathrm{P} 4 \mathrm{C}$ classes.

Part III, Theoretical Concerns of Philosophy for Children, covers five chapters addressing theoretical concerns, such as the purpose of the P4C Program about the truth or sense of meaning, the debate on paradigms of education and the introduction of $\mathrm{P} 4 \mathrm{C}$ teaching materials. It presents the purposes of developing a television series on $\mathrm{P} 4 \mathrm{C}$ called "Des enfants philosophent," which provides evidence that children under the age of 12 can engage in a philosophical inquiry. Moreover, it proposes the characteristics of a good facilitator and provides suggestions for children's books in a Community of Inquiry (CoI). It also claims that it is appropriate to use $\mathrm{P} 4 \mathrm{C}$ or $\mathrm{CoI}$ in the teaching of science, mathematics or other subjects in schools. Furthermore, it argues that participations in CoI make students to be a good thinker and outlines the characteristics of a good thinker. It also contrasts the reflective paradigm of education with the traditional paradigm and points out the shortcomings and strengths of children's literature and purpose-written story materials for $\mathrm{P} 4 \mathrm{C}$ classes. In addition, it discusses the features of $\mathrm{P} 4 \mathrm{C}$ stories and the relevant philosophical texts, as well as emphasizing the importance of the teachers' knowledge and personal reading of philosophy. Finally, it addresses the contribution of philosophy to the $\mathrm{P} 4 \mathrm{C}$ movement, the link between $\mathrm{P} 4 \mathrm{C}$, developmental psychology and Piaget's work, as well as the achievements of P4C in the teaching of the sciences and mathematics. 
Part IV, The Practice of Philosophy for Children Worldwide, consists of eight chapters dealing with the practice of $\mathrm{P} 4 \mathrm{C}$ in different countries. For example, it is interesting to know that teachers in Denmark are free to choose their own methods of teaching, such as Philosophy for Children; there is no curriculum, only a target that should encourage each student to find their own opinion, whereas in Japan, philosophy education is not used, but only morality and literature classes in which teachers cannot develop students' ability to think and discuss with their peers, which is the essence of P4C. It also demonstrates the wonderful idea of linking Islamic philosophy/Islamic thinking to $\mathrm{P} 4 \mathrm{C}$ in Malaysia, or of using philosophical games in Russia to stimulate intellectual and moral skills.

Part V, Conclusion, concludes with two chapters, one of which provides an overview of the development of the $\mathrm{P} 4 \mathrm{C}$ movement and the divergent approaches to $\mathrm{P} 4 \mathrm{C}$, as well as the clarification of the differences between Lipman and Sharp's version of $\mathrm{P} 4 \mathrm{C}$ and other approaches. Finally, the last chapter, Postscript, adds information on the purpose of this book, the reasons of choosing the methods of interview, the advantages of the interviews and the significance and relevance of the P4C Program in the contemporary world.

It should be noted that the book masterfully provides us with the Philosophy for Children Program and various issues related to it through insightful interviews with distinguished international scholars offering different viewpoints, theories and versions of $\mathrm{P} 4 \mathrm{C}$, all of which are linked and flow together. The main shortcoming of the book, however, is that it cannot be used as a resource for teaching $\mathrm{P} 4 \mathrm{C}$ as it does not completely teach us how to integrate the program into classrooms, nor does it provide us with manuals or teaching resources, such as philosophical stories or games, which can be used in teaching and learning P4C. Nevertheless, the positive point is that the editors have done a successful job in selecting the contributing authors and featuring big names in the field, providing readers with the opportunity to learn about the prominent experts and therefore be willing, for example, to search for their works and consider their teaching methods and materials in the P4C classrooms.

Overall, the book reflects the history and development of the Philosophy for Children Program and the importance of P4C in the modern world. Indeed, it provides a variety of stimulating dialogues, which make it an impressive achievement. It also provides teachers and trainers with the appropriate knowledge that can inspire them to integrate $\mathrm{P} 4 \mathrm{C}$ into their teaching. I highly recommend it to those who are interested in or involved in learning P4C and to those who are new in this field. 